\title{
EQUILÍBRIO HIDROELETROLÍTICO E HIDRATAÇÃO NO PACIENTE CIRÚRGICO
}

\author{
HYDROELECTROLYTIC BALANCE AND HYDRATION IN SURGICAL PATIENTS
}

Reginaldo Ceneviva ${ }^{1}$, Yvone Avalloni de Morais Villela de Andrade Vicente ${ }^{2}$

\begin{abstract}
${ }^{1}$ Docente, Divisão de Gastroenterologia Cirúrgica. ${ }^{2}$ Docente, Divisão de Cirurgia Pediátrica. Departamento de Cirurgia e Anatomia da Faculdade de Medicina de Ribeirão Preto-USP.

CorRespondência: Departamento de Cirurgia e Anatomia da Faculdade de Medicina de Ribeirão Preto-USP. Av. Bandeirantes, 3900, Campus Universitário da USP. 14048-900 - Ribeirão Preto / SP. email: rcenevi@fmrp.usp.br
\end{abstract}

Ceneviva R, Vicente YAMVA. Equilíbrio hidroeletrolítico e hidratação no paciente cirúrgico. Medicina (Ribeirão Preto) 2008; 41 (3): 287-300.

RESUMO: O equilíbrio hidroeletrolítico no paciente cirúrgico é um dOs principais fundamentos em clínica cirúrgica. Neste tópico são apresentadas a distribuição eletrolítica dos compartimentos hídricos, a relação entre entrada e perda de água e os principais distúrbios hidroeletrolíticos. Ao final é abordada a hidratação e reposição eletrolítica do paciente cirúrgico.

Descritores: Hidratação. Equilíbrio Hidro-Eletrolítico. Cirurgia.

\section{1- INTRODUÇÃO}

A importância da água não se restringe ao fato de ser ela o maior componente do organismo, mas também pelo papel fundamental que desempenha no metabolismo em geral.

A proporção de água na constituição dos diferentes órgãos e tecidos varia amplamente, desde 3\% no esmalte dentário até mais de $73 \%$ nos músculos estriados e tecido nervoso central.

A água corresponde em média a $60 \%$ do peso corporal no homem adulto normal com idade entre 18 e 40 anos e varia de acordo com sexo, idade e biótipo; proporcionalmente sua quantidade é maior na criança, sobretudo até 12 meses de idade, e menor no idoso. A mulher adulta normal tem em média 50\% de água, 30\% de gordura e $20 \%$ de outros tecidos. Em princípio, a água corporal varia em relação inversa à quantidade de gordura. A Tabela I exemplifica essa relação.

A proporção da massa magra é constante, independentemente do biótipo. A menor proporção de água nas pessoas obesas explica porque elas resistem menos à desidratação aguda do que as magras; por outro lado, as pessoas magras resistem menos às doenças consuntivas por ter menos gordura, portanto, menor fonte de calorias.

Tabela I: Proporção percentual da água de acordo com a constituição individual

\begin{tabular}{lccc}
\hline Paciente & Massa magra & Gordura & Água \\
\hline Normal & 20 & 20 & 60 \\
Magro & 20 & 15 & 65 \\
Obeso & 20 & 25 & 55 \\
\hline
\end{tabular}

\section{2- COMPARTIMENTOS HÍDRICOS}

A água total do organismo distribui se em dois grandes compartimentos:

\section{1- Intracelular}

O líqüido intracelular (LIC) corresponde aproximadamente a $40 \%$ do peso corporal de um adulto 
jovem do sexo masculino e de constituição média. $\mathrm{O}$ volume de água intracelular é estimado indiretamente, medindo se a água total com radioisótopo e deste volume subtrai se o volume extracelular.

\section{2- Extracelular}

O líqüido extracelular (LEC) corresponde a $20 \%$ do peso corporal e compreende dois subcompartimentos: o intravascular (5\% do peso corporal) e o intersticial ( $15 \%$ do peso corporal). O volume extracelular é mensurado por métodos dilucionais; o interstício não pode ser medido diretamente nas dosagens de diluição do indicador consiste na diferença entre o líquido extracelular total e o volume de líquido intravascular.

A distribuição de água varia de acordo com a idade. 0 interstício corresponde a $45 \%$ no recém nascido, a $30 \%$ no lactente e a $15 \%$ no adulto, o que explica a facilidade de trocas hídricas na criança de até 2 anos, quando a desidratação não tratada a tempo é importante causa de morte. A volemia também é relativamente maior na criança: é de 8 a $9 \%$, enquanto no adulto normal é de $7 \%$ do peso corporal.

Existem inúmeras substâncias envolvidas na água e entre elas os eletrólitos que, além de suas ações específicas, exercem pressão osmótica.

Água e eletrólitos estão em equilíbrio dinâmico entre os vários compartimentos, estes separados en- tre si por membranas semipermeáveis: o intracelular do interstício pela membrana celular e o interstício do intravascular pelo endotélio.

A distribuição dos principais eletrólitos nos diversos compartimentos está representada na Tabela II.

Existe eletroneutralidade em cada compartimento hídrico, isto é, a soma dos cátions equivale se à soma dos ânions no mesmo espaço.

A água transcelular é a naturalmente contida em cavidades naturais como espaço liqüórico, pleura, peritônio, articulações, tubo digestivo e corresponde a 1 a $3 \%$ do peso corporal.

Além dos dois grandes compartimentos hídricos do organismo, intracelular e extracelular, em circunstâncias especiais pode se formar um "terceiro espaço" que corresponde a uma perda interna de água, eletrólitos e proteínas, isotônico com o plasma ou ligeiramente hipotônico, na forma de edema na área traumática, cirúrgica ou não, edema do peritônio e do mesentério, derrame pleural, ascite, sucos digestivos estagnados nas alças intestinais. Esta seqüestração pode corresponder a uma perda de vários litros de água, por exemplo, na peritonite generalizada por úlcera péptica perfurada ou por pancreatite aguda, na obstrução intestinal ou ainda nas cirurgias de grande porte em que a área de dissecção for muito extensa. A perda é, em princípio, provisória e a água seqüestrada retorna para o compartimento intravascular à medida que há resolução do terceiro espaço.

\begin{tabular}{|lccc|}
\hline \multicolumn{4}{|l|}{ Tabela II: Distribuição dos eletrólitos nos compartimentos aquosos (mEq/l) } \\
\hline Cátions & Intravascular & Intersticial & Intracelular \\
$\mathrm{Na}+$ & 143 & 147 & 14 \\
$\mathrm{~K}+$ & 5 & 4 & 140 \\
$\mathrm{Ca}+$ & 5 & 2 & 5 \\
$\mathrm{Mg}++$ & 2 & 2 & 25 \\
\hline Total & $\mathbf{1 5 5}$ & $\mathbf{1 5 5}$ & $\mathbf{1 8 4}$ \\
\hline & & & \\
Ânions & Intravascular & Intersticial \\
Bicarbonato & 27 & 30 & Intracelular \\
Cloretos & 104 & 114 & 10 \\
Fosfato & 2 & 2 & 25 \\
Sulfato & 1 & 2 & 80 \\
Ác.orgânicos & 5 & 6 & 20 \\
Proteínas & 16 & 1 & $\mathrm{O}$ \\
\hline Total & $\mathbf{1 5 5}$ & $\mathbf{1 5 5}$ & 49 \\
\hline
\end{tabular}




\section{3- TROCAS ENTRE OS COMPARTIMENTOS}

Os compartimentos hídricos não são herméticos, existe um equilíbrio dinâmico envolvendo as trocas intercompartimentais, importante para a manutenção da homeostase.

As trocas de água e eletrólitos entre os compartimentos são regidas por leis físicas, pelo que, em condições fisiológicas, não há variações importantes na composição dos diversos compartimentos.

As trocas entre o plasma e o interstício dependem do gradiente entre a pressão hidrostática e a pressão coloidosmótica nos capilares (lei de Starling e equilíbrio de Gibbs Donnan). No pólo arterial há passagem de líqüido do intravascular para o interstício (filtração) em decorrência do predomínio da pressão hidrostática sobre a coloidosmótica; no pólo venular o gradiente inverte se em função da queda da pressão hidrostática, resultando na passagem de líquuido intersticial para o intravascular (absorção).

As trocas entre o setor extracelular e o intracelular baseiam se no equilíbrio osmótico. As diferenças de composição iônica entre os dois setores resultam do transporte ativo de íons dependente da energia liberada pelo metabolismo celular; esse mecanismo, conhecido como bomba de sódio, exige normalidade celular e explica a prevalência do $\mathrm{Na}^{+}$extracelular. $\mathrm{O}$ excesso de $\mathrm{Na}^{+}$é jogado para fora da célula, levando $\mathrm{K}^{+}$para dentro dela.

Na vigência de acidose, $\mathrm{H}^{+}$entra na célula e é trocado por $\mathrm{K}^{+}$que passa para o extracelular como um dos mecanismos de compensação do equilíbrio ácido base.

Quando a célula perde a vitalidade há prejuízo desse transporte ativo, aumentando a concentração de $\mathrm{K}^{+}$fora da célula e de $\mathrm{Na}^{+}$dentro dela.

O sódio é o cátion fundamental e o cloro é o ânion fundamental do espaço extracelular, sem diferença importante entre o interstício e o intravascular. O sódio é importante a ponto de se poder utilizar, na prática, seu valor no plasma como referência na estimativa da osmolaridade do espaço extracelular.

A quantidade de proteínas é maior no compartimento intravascular que no intersticial, porque a membrana capilar não é permeável às proteínas plasmáticas. As proteínas são carregadas negativamente pelo que, para se manter a eletroneutralidade, resulta concentração menor de outros ânions no plasma do que na água intersticial.
No espaço intracelular o cátion fundamental, em termos de concentração, é o potássio, e o ânion é o fosfato.

\section{4- BALANÇO HÍDRICO}

O adulto normal recebe e elimina aproximadamente 1500 a $2500 \mathrm{ml}$ de água por dia (Tabela III).

Tabela III: Balanço hídrico diário normal no adulto

\begin{tabular}{lcrc}
\multicolumn{2}{c}{ Entrada $(\mathbf{m l} / \mathbf{2 4} \mathbf{h})$} & \multicolumn{2}{c}{ Perda $(\mathbf{m l} / \mathbf{2 4 h})$} \\
\hline Alimentos líqüidos & $700-1500$ & Rins & $800-1500$ \\
Alimentos sólidos & $600-700$ & Pulmões & $200-300$ \\
Água de oxidação & $200-300$ & Pele & $400-500$ \\
& & Fezes & $100-200$ \\
\hline Total & $1500-2500$ & & $1500-2500$ \\
\hline
\end{tabular}

\section{1- Entradas}

A ingestão normal de alimentos proporciona ao organismo a entrada adequada de água e nutrientes.

A proporção da água, como componente dos alimentos sólidos, varia entre 50 e $90 \%$.

O cloro e o sódio são ingeridos sob a forma de sal, como condimento e, como componentes, em proporções diversas, de diferentes alimentos.

As entradas são normalmente reguladas pelas sensações, que estimulam a tomar maior quantidade de um ou outro alimento. A sede é um estímulo à íngestão de água ou de alimentos que a contenham em grandes proporções, como as frutas; em certos momentos prefere se alimentos salgados ou insosos, etc.

À parte hábitos aberrantes, a sede e o apetite específico refletem as necessidades do meio interno, e naturalmente controlam a entrada por via oral da quantidade adequada de água e sais. Para essa ingestão seletiva é necessário nível adequado de consciência.

Em situações clínicas diversas, em que a consciência está prejudicada ou a via natural de entrada (oral) não é factível ou deva ser evitada, a administração de água e eletrólitos deve ser feita por via extraordinária (venosa) e deve visar o equilíbrio entre entradas e perdas.

A água de oxidação ou endógena é resultante do metabolismo dos alimentos (hidratos de carbono, proteínas e gorduras) ou da degradação de tecidos 
orgânicos. Com o aumento do metabolismo, como por exemplo na resposta endocrinometabólica ao trauma, a água endógena aumenta e pode ultrapassar $700 \mathrm{ml}$ por dia.

\section{2- Perdas}

\subsection{1- Renal}

Os rins constituem a principal sentinela do organismo quanto à homeostase do meio interno, sendo capazes de excretar urina escassa ou abundante, concentrada ou diluída, ácida ou alcalina, tendendo sempre a conservar no organismo níveis normais de água e sais, apesar das variações na ingestão.

A perda que se processa através dos rins é extremamente variável em quantidade de água e conteúdo de sais.

O rim normal do adulto em circunstâncias fisiológicas e dieta livre elimina diariamente de 700 a 1500 $\mathrm{ml}$ de urina, contendo por litro em média $140 \mathrm{mEq}$ de sódio, $130 \mathrm{mEq}$ de cloro e $35 \mathrm{mEq}$ de potássio.

Algumas situações clínicas podem alterar a função renal no controle do equilíbrio hidroeletrolítico.

- Rim normal submetido à ação hormonal. Das alterações hormonais significantes, a mais frequientemente encontrada na prática é a resultante da reação orgânica e metabólica ao trauma e leva a alterações importantes na composição da urina, independentemente das entradas e da situação bioquímica do meio interno.

Da maior liberação do hormônio anti diurético decorre redução na diurese que pode alcançar valores menores que $800 \mathrm{ml}$ nas primeiras 24 horas que se seguem à agressão que provocou a situação de estresse; esta diminuição não dura geralmente mais que um dia.

A maior produção de aldosterona resulta em diminuição brusca da concentração de $\mathrm{Na}^{+}$e $\mathrm{CI}^{-}$na urina, baixando as taxas para 20 a $30 \mathrm{mEq} / \mathrm{l}$; o retorno à normalidade pode demorar mais que 5 dias, após ter cessado a situação de estresse. $\mathrm{O}$ aumento da aldosterona leva ainda à maior eliminação de $\mathrm{K}^{+}$na urina, alcançando cifras de 80 a $100 \mathrm{mEq} / \mathrm{l}$ voltando ao normal também após terminado o estresse.

- Rim normal submetido à ação de diurético. A ação do diurético determina a quantidade de sais e água eliminada pelos rins, independentemente da situação do meio interno. Sob a ação das clorotiazidas, por exemplo, a eliminação urinária de $\mathrm{Na}^{+} \mathrm{e} \mathrm{K}^{+}$con- tinua aumentada mesmo na vigência da depleção desses íons no organismo.

Na terapêutica com diuréticos os rins podem eliminar $\mathrm{Na}^{+}, \mathrm{CI}$ e $\mathrm{K}^{+}$em concentrações normais, porém em volume maior de urina, aumentando a perda total desses íons.

- Rim doente. Na insuficiência renal, a oligúria acompanha se de diminuição da capacidade renal de concentração e de diluição, favorecendo a eliminação de taxas reduzidas e constantes de $\mathrm{Na}^{+}, \mathrm{CI}^{-}$e $\mathrm{K}^{+}$; qualquer que seja a situação bioquímica do meio interno, haverá retenção desses íons se for mantida sua entrada normal, com risco maior relacionado à retenção de $\mathrm{K}^{+}$.

\section{3- Cutânea e pulmonar}

A perda pela perspiração cutânea é de água praticamente sem eletrólitos e, como a perda pulmonar, é insensível. A saída de água pelos pulmões é acompanhada somente por $\mathrm{CO}_{2}$; essa perda é de água pura, sem conteúdo salino.

A perda cutânea pulmonar aumenta com a febre e a taquipnéia e em decorrência do trauma cirúrgico.

A febre aumenta a evaporação e a freqüência respiratória. Admite se que cada grau de temperatura acima de $37^{\circ} \mathrm{C}$ mantido durante 24 horas corresponde a um aumento de até $500 \mathrm{ml}$ de perda hídrica neste período de tempo.

A sudorese, ao contrário, representa perda não somente de água, mas também de eletrólitos e, quando manifesta, deve ser considerada como perda extraordinária; quando intensa e mantida pode corresponder à perda de até mais de $1000 \mathrm{ml}$ nas 24 horas; o conteúdo de $\mathrm{Na}^{+}$e de $\mathrm{CI}^{-}$varia, para cada íon, entre 10 e $70 \mathrm{mEq} / \mathrm{l}$.

A perda de água pelos pulmões aumenta na taquipnéia e diminui na bradpnéia, podendo ser acompanhada por alterações do equilíbrio ácido base, respectivamente alcalose respiratória e acidose respiratória. A traqueostomia e a assistência respiratória tornam a perda de água pelos pulmões mais expressiva.

\section{4- Digestiva}

As secreções digestivas somam de 6000 a $8.200 \mathrm{ml}$ por dia (Tabela IV).

Em condições fisiológicas normais, a água e os eletrólitos ingeridos, somados à água e eletrólitos das 


\begin{tabular}{lrrrrr}
\multicolumn{6}{c}{ Tabela IV: Composição eletrolítica (mEq/l e volume diário $(\mathbf{m I})$ das secreções do tubo digestivo } \\
\hline Secreção & $\mathrm{Na}^{+}$ & $\mathrm{K}^{+}$ & $\mathrm{Cl}^{-}$ & $\mathrm{HCO}_{3}$ & Volume \\
\hline Salivar & 35 & 26 & 35 & 15 & 1500 \\
Gástrica & 60 & 10 & 100 & 8 & 2500 \\
Biliar & 146 & 5 & 100 & 40 & 500 \\
Pancreática & 140 & 5 & 75 & 120 & 700 \\
Intestinal (intestino delgado) & 110 & 5 & 100 & 30 & \\
lleal & 120 & 15 & 105 & 20 & \\
Cecal & 80 & 20 & 45 & - & \\
\hline
\end{tabular}

Intestinal (total)

secreções digestivas, são quase totalmente absorvidos no intestino, de tal maneira que apenas 100 a 200 $\mathrm{ml}$ de água são habitualmente eliminados nas fezes no período de 24 horas.

Perdas digestivas extraordinárias podem ocorrer em diversas situações como diarréia profusa, fístulas digestivas, vômitos, aspiração por sonda nasogástrica, íleo adinâmico, obstrução intestinal, podendo atingir até mais de 6 litros por dia.

As secreções digestivas, com exceção da pancreática e biliar, são discretamente hipotônicas em relação ao plasma; a bile é praticamente isosmótica e a pancreática discretamente hiperosmótica.

A perda intensa de suco gástrico por estenose decorrente de úlcera péptica (pré pilórica ou duodenal), resulta em alcalose metabólica hipoclorêmica pela perda de ácido clorídrico.

As perdas de secreções do trato digestivo distal ao piloro podem levar à acidose metabólica.

O íleo adinâmico pós operatório bloqueia a absorção intestinal, levando à estase das secreções digestivas na luz gástrica e intestinal, o que corresponde, transitoriamente, à perda interna significante de líqüido isotônico; essas secreções permanecem na luz intestinal e às vezes são parcialmente eliminadas mediante vômitos ou drenagem com sondas apropriadas.

\section{5- ALTERAÇÕES DO EQUILÍBRIO HÍDRICO E ELETROLÍTICO}

\section{1- Alterações do equilíbrio hídrico}

As alterações hidroeletrolíticas iniciam se sempre no compartimento extracelular e podem ou não repercutir em alterações do intracelular.

\subsection{1- Desidratação}

A desidratação decorre da deficiência de entradas e/ou excesso de perdas de água. Pode ser classificada, de acordo com a tonicidade do espaço extracelular, em isotônica, hipotônica e hipertônica.

As causas mais frequientes de desidratação são: falta de ingestão ou perdas extraordinárias pelas vias ordinárias (perspiração cutâneo pulmonar, poliúria, diarréia) ou por vias extraordinárias (vômitos, aspiração gastrointestinal, íleo adinâmico, fístulas digestivas).

A desidratação caracteriza se clinicamente por sede, oligúria, perda de peso, secura da língua, olhos encovados, diminuição da elasticidade da pele, rolete muscular, hipotensão postural, taquicardia, pulso fraco, obnubilação, febre e coma.

A desidratação pode levar também à alteração de exames laboratoriais, tais como: aumento na taxa de hemoglobina, hematócrito, proteínas totais, uréia, creatinina no sangue, redução da volemia e aumento da densidade urinária e da concentração da uréia na urina.

A concentração de $\mathrm{Na}^{+}$difere, porém, nos diferentes tipos de desidratação e as define como iso, hipo ou hipertônica; a desidratação deve ser tratada mediante administração de líquiidos, em volume e qualidade dependentes do diagnóstico da gravidade e do tipo de desidratação.

A definição da gravidade da desidratação pode ser feita com base na perda de peso corporal e sobretudo na avaliação conjunta da intensidade de sintomas e sinais clínicos e das alterações laboratoriais.

Quanto à perda de peso corporal, a desidratação é leve com perda menor que 5\% do peso corpóreo, moderada com perda entre $5 \%$ e $8 \%$ e grave com perda maior que $8 \%$. 
A definição da gravidade da desidratação fornece estimativa aproximada da quantidade de água perdida e, assim, do volume a ser reposto. A quantidade de água a ser administrada, porém, é melhor definida pela resposta individual à terapêutica, mediante $o$ desaparecimento de sinais e sintomas da deficiência de água e correspondente retorno à normalidade dos dados laboratoriais e da diurese.

O diagnóstico do tipo de desidratação quanto à tonicidade, por outro lado, define a qualidade da solução a ser ministrada na reposição.

\section{- Desidratação isotônica}

As causas relacionam se com a perda não compensada de líquiidos isotônicos perdas digestivas agudas (vômitos, diarréia, fístulas digestivas), sequiestro no terceiro espaço (íleo adinâmico, peritonite, grandes áreas de dissecção cirúrgica), paracentese.

O quadro clínico inclui os sintomas e sinais da desidratação em geral, sobretudo os relacionados à diminuição do espaço extracelular (oligúria e em casos graves choque hipovolêmico).

O comportamento dos espaços hídricos caracteriza se pela retração exclusiva do extracelular que, por ser isotônica, não favorece trocas extraordinárias com o intracelular (Figura 1). No esquema de Darrow o eixo horizontal representa o volume e o vertical representa a tonicidade dos espaços hídricos: extracelular (EC) e intracelular (IC).

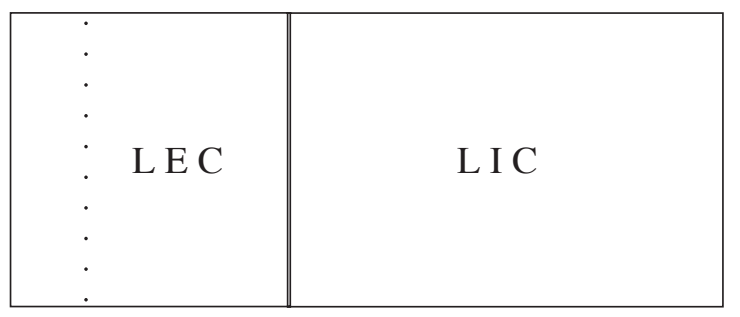

Figura 1. Desidratação isotônica. A retração isotônica do espaço extracelular está representada pela linha pontilhada.

O tratamento da desidratação isotônica consiste na administração de soluções isotônicas.

\section{- Desidratação hipotônica}

As causas relacionam se com a administração insuficiente de água e sobretudo de sais ou à perda não compensada maior de sais que de água: perdas digestivas crônicas isotônicas (vômitos, diarréia, fístulas) tratadas com soluções hipotônicas, hipoaldosteronismo primário, perda salina em nefropatas, etc.
As alterações compartimentais primárias são redução de volume e da tonicidade do espaço extracelular. Como consequiência dessa hipotonicidade passa água do espaço extracelular para o intracelular até que se estabeleça o equilíbrio osmótico, associando se expansão do volume e hipotonicidade do intracelular; esta situação, com retração do extracelular e expansão do intracelular, ambas hipotônicas, caracteriza a desidratação hipotônica (Figura 2).

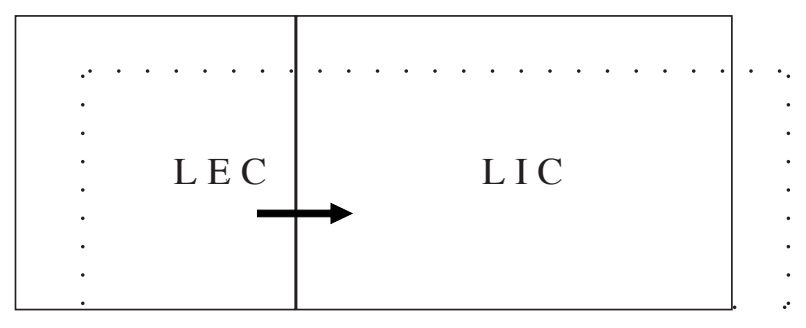

Figura 2. Desidratação hipotônica. As linhas pontilhadas representam a retração hipotônica do espaço extracelular e a expansão hipotônica intracelular, e a seta representa o sentido de passagem da água.

Os sintomas dependem da redução do espaço extracelular (choque hipovolêmico, oligúria), da expansão do intracelular (sialorréia, diarréia, vômitos) e da redução das taxas de $\mathrm{Na}^{+}$e de $\mathrm{CI}^{-}$(astenia, tremores, íleo adinâmico, choque).

A escolha da solução a ser ministrada depende do grau de hipotonicidade do líquiido extracelular. Se a hiponatremia é leve a correção é feita apenas com solução isotônica; se a hipotonicidade é acentuada com $\mathrm{Na}+$ plasmático abaixo de $120 \mathrm{mEq} / \mathrm{l}$ e, principalmente, se a manifestação clínica é importante, inicia se o tratamento com solução hipertônica de $\mathrm{NaCI}$ (300 ou $500 \mathrm{ml}$ de $\mathrm{NaCI} 5 \%$ ou $3 \%$ no adulto) e, a seguir, para complementar a correção da desidratação administra se solução salina isotônica.

\section{- Desidratação hipertônica}

As causas mais comuns são a perda de líquiido hipotônico na perspiração pulmonar acentuada, sudorese, diabete insípido, diurese osmótica por hiperglicemia e a oferta insuficiente de líqüido durante nutrição enteral ou parenteral.

$\mathrm{O}$ aumento da tonicidade do compartimento extracelular favorece a passagem de água do intracelular para o extracelular, com redução do volume e aumento da tonicidade também do intracelular (Figura 3); a desidratação hipertônica é também chamada de dessecação. 


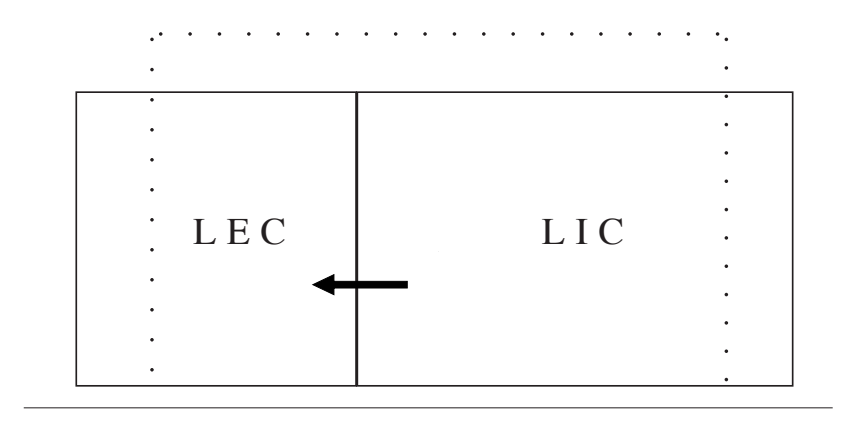

Figura 3. Desidratação hipertônica. As linhas pontilhadas representam a retração hipertônica dos espaços extracelular e intracelular e a seta representa o sentido de passagem da água.

Além dos sintomas e sinais da desidratação em geral, com sede intensa e oligúria acentuada, os pacientes podem apresentar febre, agitação psicomotora, confusão mental e coma.

O tratamento baseia se na supressão da entrada de sais e infusão de solução hipotônica (glicosada $5 \%$ ) até que a tonicidade seja corrigida, seguindo se, se necessário, de solução isotônica.

Para a correção dos diferentes tipos de desidratação a quantidade de água a ser ministrada é a necessária para o retorno da normalidade do estado hídrico, estimada pelo desaparecimento dos sintomas e sinais de desidratação, e pelo restabelecimento do volume urinário horário normal, entre 30 a 60 mEq/l no adulto.

Recomenda se a oferta de $\mathrm{K}^{+}$somente após diurese mínima de $800 \mathrm{ml}$, com densidade urinária maior ou igual a 1018.

\subsection{2- Superhidratação}

Desenvolve se, teoricamente, na vigência de oferta exagerada e/ou perda insuficiente de água. $\mathrm{Na}$ prática, porém, o rim normal e não sujeito à ação hormonal é capaz de eliminar o excesso de oferta de água e a superhidratação resulta sempre por perda insuficiente.

A superhidratação acompanha se do aumento da volemia, diluição do plasma, com redução relativa das taxas de hemácias, de hemoglobina, do hematócrito e de proteínas totais no plasma.

Na prática clínica não se percebe a superhidratação hipertônica, somente possível se iatrogênica pela administração exagerada de líqüido hipertônico em paciente com perda insuficiente.

\section{- Superhidratação isotônica}

As causas mais comuns são: cardíaca, renal e hepática.
Existe aumento do líquido extracelular que, por ser isotônico, se mantém restrito a esse compartimento (Figura 4).

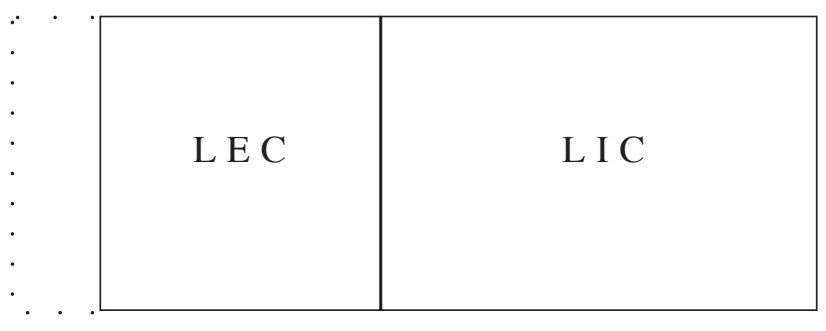

Figura 4. Superhidratação isotônica. As linhas pontilhadas representam o aumento isotônico do espaço extracelular

O quadro clínico corresponde a sintomas e sinais de retenção hídrica e da doença básica, insuficiência cardíaca, renal ou hepática. Assim, podem estar presentes edema subcutâneo, derrame pleural, ascite, estertores pulmonares, dispnéia, oligúria, aumento do peso corpóreo, icterícia, alterações neurológicas.

O tratamento, além de medidas restritivas, pode incluir, na medida da gravidade e da etiologia da superhidratação, dieta hipossódica, diuréticos, cardiotônicos e mesmo diálise peritoneal ou hemodiálise. Não se deve dar diuréticos até que seja analisada a causa do edema. Os diuréticos usados sem critério podem induzir a distúrbios eletrolíticos, coma hepático, azotemia e arritmias cardíacas.

\section{- Superhidratação hipotônica}

A causa é a excessiva oferta de água na presença de baixa diurese. A fonte de água pode ser a ingestão oral, mas, mais freqüentemente, é a excessiva administração parenteral de água com glicose.

Os pacientes com doenças crônicas debilitantes, com câncer, insuficiência cardíaca congestiva ou insuficiência hepática ou renal, são propensos a ter expansão do espaço extracelular com hipotonicidade antes de se submeterem à cirurgia; no período pósoperatório tendem a expandir e diluir mais o espaço extracelular.

Em decorrência da hipotonicidade do compartimento extracelular passa água para o intracelular, que também tem sua tonicidade gradativamente diminuída à medida que seu volume se expande (Figura 5). A superhidratação hipotônica é também chamada de intoxicação hídrica.

Náuseas, vômitos, astenia e queda do volume urinário são manifestações clínicas precoces, podendo 


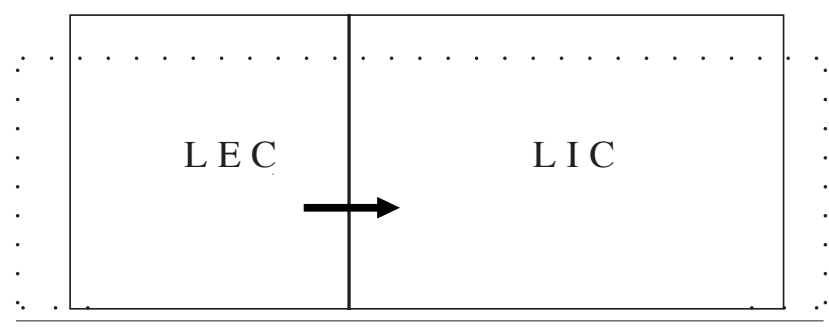

Figura 5. Superhidratação hipotônica. As linhas pontilhadas representam a expansão hipotônica dos espaços extracelular e intracelular e a seta representa o sentido de passagem da água.

ser seguidas por alterações como sialorréia, diarréia, convulsões e coma; essas alterações neurológicas são decorrentes de edema cerebral. Há sempre aumento do peso corporal, podendo observar se edemas periférico e pulmonar.

Os achados laboratoriais incluem rápida queda na concentração do $\mathrm{Na}^{+}$sérico e na osmolaridade plasmática. A urina pode conter quantidade substancial de $\mathrm{Na}^{+}$que, na presença de baixa concentração plasmática, indica inapropriada liberação de $\mathrm{Na}^{+}$decorrente do excesso de volume do líquiido extracelular, se estiverem afastadas doença renal e insuficiência adrenal.

0 tratamento da superhidratação hipotônica baseia se na restrição hídrica, reposição de $\mathrm{Na}^{+}$mediante administração de solução salina hipertônica em pequenas quantidades (300 ml de $\mathrm{NaCI} 3 \%$ ), uso cuidadoso de diurético osmótico (Manitol) e administração lenta de glicose hipertônica. Nenhuma tentativa deve ser feita para reposição calculada da deficiência de sódio com base no volume do espaço extracelular e na deficiência de $\mathrm{Na}^{+}$, porque resultará em grave sobrecarga. A perda insensível de água pela perspiração cutâneo pulmonar e o fluxo urinário podem, gradualmente e por si só, restabelecer a normalidade.

\section{2- Alterações do equilíbrio eletrolítico}

\subsection{1- Alterações do Sódio}

$0 \mathrm{Na}^{+}$é o principal cátion do LEC onde apresenta taxa de concentração entre 138 e 145 mEq/l, com média de $142 \mathrm{mEq} / \mathrm{l}$.

\section{- Hiponatremia}

Diversas causas podem levar à hiponatremia. A hiponatremia absoluta pode desenvolver se por ingestão insuficiente (dieta hipossódica recomendada para nefropatas) ou por perdas renais e extra renais exageradas como poliúria, diarréia crônica e aspiração gastrointestinal; nefropatias perdedoras de $\mathrm{Na}^{+}$, freqüentemente associadas a drogas e infecção, e o uso abusivo de diuréticos e insuficência adrenal são situações que acarretam perda importante de $\mathrm{Na}^{+}$, condicionando a hiponatremia.

A hiponatremia de diluição desenvolve se pela sobrecarga hídrica que quase sempre é uma inadequação terapêutica, que ocorre quando o organismo perde secreção contendo sódio e a reposição se faz apenas com solução glicosada ou com soluções hipotônicas; a oferta apenas dessas soluções no período pós operatório imediato, quando em decorrência da reação endócrino metabólica há diminuição da perda renal de água, também pode levar à hiponatremia de diluição. A hiponatremia dilucional pode ocorrer também na insuficiência cardíaca congestiva, cirrose hepática, doença renal com oligúria, secreção inadequada do hormônio anti diurético e doença de Addison.

É importante diferenciar o tipo de hiponatremia presente, se absoluta ou dílucional, porque o tratamento é diferente (Tabela V).

Tabela V: Diagnóstico diferencial da hiponatremia

\begin{tabular}{lcc}
\hline Pele & $\begin{array}{c}\text { Hiponatremia absoluta } \\
\text { (depleção de sódio) }\end{array}$ & $\begin{array}{c}\text { Hiponatremia de diluição } \\
\text { (intoxicação hídrica) }\end{array}$ \\
Mucosas & fria, pastosa & normal, úmida \\
Turgor cutâneo & secas & úmidas \\
Edema & diminuído & normal \\
Pulso & ausente & às vezes presente \\
Pressão arterial & rápido & normal \\
Urina & geralmente baixa & normal \\
Hematócrito & escassa & normal ou poliúria, diluída \\
Uréia & elevado & normal ou diminuído \\
& elevada & normal \\
\hline
\end{tabular}


Considera se hiponatremia grave quando a concentração de $\mathrm{Na}+$ plasmático for igual ou menor que $120 \mathrm{mEq} / \mathrm{l}$.

Os sinais e sintomas mais comuns são astenia, oligúria, dificuldade na concentração mental, alterações da personalidade, taquicardia, tendência a choque circulatório, confusão, delírio e coma. Os sintomas geralmente manifestam se quando o $\mathrm{Na}^{+}$cai para valores iguais ou menores que $120 \mathrm{mEq} / \mathrm{l}$.

No tratamento da hiponatremia absoluta (depleção de $\mathrm{Na}^{+}$) administra se $\mathrm{Na}^{+}$para a manutenção, que corresponde à perda de água prevista nas próximas 24 horas e para a reparação, que é o déficit existente de $\mathrm{Na}^{+}$. Calcula se o déficit de $\mathrm{Na}^{\prime}$ com base no volume de água extracelular (20\% do peso corporal), onde está a maior parte do $\mathrm{Na}^{+}$e que corresponde ao valor estimado laboratorialmente. A manutenção é obrigatória; se o déficit de $\mathrm{Na}^{+}$é muito grande, a reparação pode ser feita parceladamente, por exemplo, em 2 dias.

Na hiponatremia por diluição, que corresponde à intoxicação hídrica, o tratamento visa sobretudo à eliminação do excesso de água mediante uso de diurético osmótico (Manitol); reposição de $\mathrm{Na}^{+}$somente em casos com concentração de $\mathrm{Na}^{+}$abaixo de 110 $\mathrm{mEq} / \mathrm{l}$, observando se cuidadosamente sinais de insuficiência cardíaca.

\section{- Hipernatremia}

É menos freqüente que a hiponatremia e pode ser decorrente de perda de água proporcionalmente maior que a de $\mathrm{Na}+$ (diabetes insípido, diabete mellitus, febre, insolação, hiperventilação), reposição insuficiente de perdas hídricas (redução da ingestão hídrica por náuseas, vômitos ou incapacidade fisica), administração excessiva de solutos em pacientes renais (sal na alimentação por sonda, diuréticos osmóticos, diálise peritoneal), excesso de esteróides.

Considera se hipernatremia grave quando o $\mathrm{Na}+$ alcança $160 \mathrm{mEq} / \mathrm{l}$.

O quadro clínico é caracterizado por sede, oligúria, mucosas secas, febre, taquipnéia e alterações neurológicas que podem ser variadas, incluindo tremor, hiperreflexia profunda, confusão mental, alucinações e coma agitado.

Trata se a doença base, suprime se temporariamente a entrada de $\mathrm{Na}^{+}$e faz se a reposição hídrica mediante infusão de solução glicosada 5\%, administrando se metade do volume nas primeiras 8-12 horas. A reposição muito rápida pode complicar se com edema cerebral.

\subsection{2- Alterações do Cloro}

O cloro é o principal ânion do espaço extracelular, com taxa de concentração entre 95 e 105 mEq/ le média de $103 \mathrm{mEq} / \mathrm{l}$.

As alterações do CI geralmente acompanham as do $\mathrm{Na}^{+}$.

\section{- Hipocloremia}

As causas de hipocloremia absoluta (depleção de cloro) são por falta de entrada adequada de $\mathrm{CI}^{-}$, geralmente em dietas prolongadas sem ou com pouco sal) e por eliminação exagerada por poliúria, vômitos, aspiração gástrica. A perda de $\mathrm{CI}^{-}$por vômitos ou por aspiração gástrica pode associar se à alcalose metabólica por perda concomitante de $\mathrm{H}^{+}$.

A hipocloremia dilucional (intoxicação hídrica) pode desenvolver se por administração excessiva de água em pacientes anúricos ou oligúricos; a quantidade total de $\mathrm{CI}^{-}$não varia, mas a concentração diminui como resultado do excesso de água.

A hipocloremia é grave quando a concentração do cloro plasmático está abaixo de $80 \mathrm{mEq} / 1$.

A deficiência de cloro caracteriza se por redução do tônus da fibra muscular lisa, principalmente do intestino e dos vasos, pelo que se manifesta clinicamente por íleo adinâmico e tardiamente por hipotensão arterial.

O tratamento da depleção de cloro é semelhante ao da depleção de sódio, fazendo se a manutenção e a reparação, esta estimada com base no volume extracelular. O tratamento da hipocloremia de diluição tem também como base o tratamento da intoxicação hídrica que visa, sobretudo, a eliminação do excesso de água.

\section{- Hipercloremia}

Tem as mesmas causas que a hipernatremia, por perda exagerada de água ou por entrada excessiva de sais em pacientes renais ou com rim submetido à ação hormonal por estresse (pós operatório imediato).

O quadro clínico caracteriza se pela presença de sede, oligúria, contrações musculares, tremores, confusão mental, estupor, febre em geral moderada.

A hipercloremia é grave quando atinge valores acima de $125 \mathrm{mEq} / \mathrm{l}$ no plasma.

Além da doença base o tratamento envolve supressão de entrada do $\mathrm{CI}^{-}$e a sua diluição no compartimento extracelular mediante infusão de solução glicosada 5\% que, como para a hipernatremia, não deve ser muito rápida pelo risco de edema cerebral. 


\subsection{3- Alterações do Potássio}

0 potássio é o principal cátion do compartimento intracelular. No compartimento extracelular sua concentração é baixa variando normalmente entre 3,5 e $4,5 \mathrm{mEq} / \mathrm{l}$.

\section{- Hipocalemia}

As causas da hipopotassernia são entrada insuficiente (geralmente por hidratação parenteral inadequada) ou perdas excessivas por poliúria (período poliúrico da insuficiência renal aguda ou por ação de diuréticos) ou por diarréia e fístulas digestivas; doença de Cushing, síndrome de Conn e desvio iônico (alcalose) também podem levar à queda do $\mathrm{K}^{+}$plasmático.

A fibra muscular é a mais afetada pela carência de $\mathrm{K}^{+}$; a hipocalemia origina hipotonia da musculatura lisa e estriada.

O quadro clínico, dependente principalmente da hipotonia muscular,

caracteriza se por astenia, fraqueza muscular, parestesias, paralisias, íleo adinâmico, irritabilidade, letargia, com arritmias cardíacas tipo bigeminismo elou trigeminismo, e risco de parada cardíaca em sístole.

O miocárdio pode apresentar alterações de repolarização, que se manifestam no traçado eletrocardiográfico sob a forma de prolongamento e depressão do espaço QT e diminuição da amplitude da onda T, que se achata com base mais ampla, chegando eventualmente a se inverter.

A hipocalemia é leve quando a concentração de $\mathrm{K}^{+}$plasmático está entre 3,5 e $3 \mathrm{mEq} / \mathrm{l}$, moderada entre 3 e $2,5 \mathrm{mEq} / \mathrm{l}$ e grave abaixo de $2,5 \mathrm{mEq} / \mathrm{l}$.

0 tratamento é a administração de $\mathrm{K}^{+}$, por via oral (KCI xarope ou drágeas, ascorbato de $\mathrm{K}^{+}$em comprimidos efervescentes) ou por via endovenosa (aumentando se a concentração de $\mathrm{K}^{+}$nas soluções eletrolíticas usuais ou na forma de solução polarizante).

$\mathrm{Na}$ compensação do déficit de $\mathrm{K}^{+}$deve se considerar que sua distribuição não é homogênea, existindo em proporção muito maior no espaço intracelular, e que as variações do $\mathrm{K}^{+}$extracelular devem estar sujeitas a limites muito estreitos.

Embora a reposição intracelular do $\mathrm{K}^{+}$possa requerer grandes quantidades, $\mathrm{o} \mathrm{K}^{+}$deve ser administrado lenta e cuidadosamente, para não produzir concentração excessiva no sangue que possa determinar parada cardíaca.

A reposição do $\mathrm{K}^{+}$faz se de maneira empírica, sendo um esquema usual a administração de 40 a 60
$\mathrm{rnEq} / \mathrm{l}$ por via endovenosa a velocidades não maiores que 30 a $40 \mathrm{mEq} / \mathrm{hora}$.

Recomenda se não ultrapassar: $0,5 \mathrm{mEq} / \mathrm{min}$, $40 \mathrm{mEq} / \mathrm{h}, 100 \mathrm{mEq} / \mathrm{dia}$.

Os pacientes cirróticos são especialmente suscetíveis a complicações da hipotassemia e devem ser tratados agressivamente na reposição do $\mathrm{K}^{+}$.

Pacientes com hipopotassernia são mais suscetíveis a arritmias cardíacas durante digitalização e também necessitam de tratamento intensivo para essa alteração eletrolítica.

Quando há necessidade de correção rápida da deficiência de $\mathrm{K}^{+}$, pode se administrar $\mathrm{K}^{+}$em solução polarizante, na qual existe $1 \mathrm{U}$ de insulina simples para cada 3 ou $4 \mathrm{~g}$ de glicose.

\section{- Hipercalemia}

A insuficiência renal é a causa mais freqüente da hipercalemia. Quando a insuficiência renal ocorre simultaneamente com a administração de potássio, a hipercalemia é obviamente mais acentuada. Doença de Addison, desvio iônico na acidose, transfusões e hemólise, lesões por esmagamento, grandes queimaduras, grandes traumatismos e outras causas de degradação de proteínas aumentam o $\mathrm{K}^{+}$no plasma se a função renal for insuficiente.

As manifestações clínicas são tardias e incluem principalmente alterações sensoriais como parestesias (face, língua, pés e mãos), paralisia flácida, arritmias cardíacas; o maior risco, contudo, é a morte súbita por parada cardíaca em diástole. As manifestações eletrocardiográficas são caracterizadas por ondas T elevadas, pontiagudas, prolongamento do intervalo $\mathrm{PR}$ e do $\mathrm{QRS}$ e ondas $\mathrm{S}$ profundas.

A hipercalemia é considerada leve quando a concentração do $\mathrm{K}^{+}$plasmático está entre 4,5 e $5 \mathrm{mEq} / \mathrm{l}$, moderada entre 5 e $6 \mathrm{mEq} / \mathrm{l}$ e grave entre $6 \mathrm{e}$ $7 \mathrm{mEq} / \mathrm{l}$; acima de $7 \mathrm{mEq} / \mathrm{l}$ é muito grave e requer tratamento urgente.

O tratamento preferencial da hiperpotassemia é a diálise, porém, medidas outras podem ser usadas quando essa não é possível.

As medidas terapêuticas possíveis são:

\section{Supressão da entrada de potássio}

Ação antagônica do cálcio: o cálcio pode ser administrado lentamente por via venosa na forma de cloreto ou gluconato de cálcio $10 \%$, na dose de $10 \mathrm{ml}$, para neutralizar a ação do $\mathrm{K}^{+}$sobre o músculo cardíaco. 
Bicarbonato de sódio: pode ser administrado nos pacientes com acidose metabólica para favorecer a entrada do $\mathrm{K}^{+}$para o espaço intracelular e reduzir a ação do $\mathrm{K}^{+}$no músculo cardíaco.

Redistribuiçâo do potássio: a administração de solução polarizante (glicose e insulina) sem $\mathrm{K}^{+}$favorece a redistribuição do $\mathrm{K}^{+}$forçando a migração do íon do compartimento extracelular para o intracelular.

Extração do $\mathrm{K}^{+}$das secreções intestinais: resinas de trocas iônicas $\left(\mathrm{Na}^{+}\right.$ou $\mathrm{Ca}^{++}$por $\left.\mathrm{K}^{+}\right)$, por via oral ou, preferencialmente por via retal, na forma de enema de retenção, retiram $\mathrm{K}^{+}$a partir de secreções digestivas.

Extração do $\mathrm{K}^{+}$do líqüiido extracelular: mediante diálise peritoneal ou extra corpórea (hemodiálise) com rim artificial.

\section{6- HIDRATAÇÃO DO PACIENTE CIRÚRGICO}

O paciente cirúrgico pode apresentar alterações do equilíbrio hidroeletrolítico (EHE) em qualquer período relacionado à intervenção cirúrgica.

No período pré operatório essas alterações podem decorrer da própria doença de base ou de problema clínico associado.

Durante a cirurgia as alterações são mais freqüentes e mais intensas nas operações mais demoradas e nas de grande porte, que requerem mais atenção e maior controle pelo anestesista, sobretudo em pacientes predispostos.

No pós operatório os distúrbios hidroeletrolíticos estão condicionados à magnitude das alterações hormonais da resposta orgânica ao trauma e ao tempo de duração da hidratação endovenosa, necessária enquanto as vias oral e enteral não forem factíveis.

Em qualquer momento, antes, durante ou após a cirurgia, todo ato relacionado à prescrição de hidratação deve ser precedido do correto diagnóstico do estado de hidratação do paciente.

\section{1- Hidratação pré-operatória}

$\mathrm{O}$ jejum de 12 horas, freqüente nos pacientes operados no período da manhã, resulta em redução de aproximadamente $800 \mathrm{ml}$ na água total do organismo e o jejum de 18 horas pode corresponder à redução de 1000 a $1500 \mathrm{ml}$ da água total.

A desidratação e a hiponatremia predispõem ao choque circulatório e à insuficiência renal.

Há geralmente, diferença no estado pré operatório de hidratação dos pacientes se a doença pela qual vão ser operados está ou não complicada. São exemplos os portadores de úlcera péptica ou de hérnia inguinal que, sem complicações, são operados eletivamente, mas a complicação da úlcera por perfuração ou da hérnia por obstrução intestinal requer cirurgia de urgência e correção dos distúrbios hidroeletrolíticos; apesar da urgência, grandes perdas hidroeletrolíticas para o terceiro espaço por edema peritoneal, seqüestração na luz intestinal e/ou vômitos são significativas e exigem reposição antes da cirurgia.

Pacientes hígidos, bem hidratados, candidatos à cirurgia eletiva de pequeno porte, não necessitam, em geral, de fluidoterapia prévia.

Para pacientes a serem submetidos à cirurgia eletiva de médio ou grande porte, principalmente nos que se prevê área extensa de dissecção, recomenda se o início da hidratação 2 a 4 horas antes da operação mediante a oferta de 800 a $1500 \mathrm{ml}$ de solução salina, de acordo com o tempo de jejum e, em princípio, o suficiente para manter volume urinário de 30 a $60 \mathrm{ml}$ por hora; este débito urinário é, nesta situação, indicativo de boa perfusão renal e sugestivo de hidratação adequada.

Na icterícia obstrutiva é importante a fluidoterapia antes da cirurgia para se evitar lesões renais pelo depósito de pigmentos biliares .

No politraumatizado, sobretudo com trauma grave, a hipovolemia é decorrente da perda de sangue. De acordo com os critérios do ATLS (Advanced Trauma Life Support) o atendimento inicial prevê infusão rápida de 2 litros de solução de lactato de Ringer (solução balanceada isotônica) e, dependendo da resposta renal e hemodinâmica e dos índices hematimétricos, hemoterapia seletiva com administração específica de componentes do sangue.

\section{2- Hidratação intra-operatória}

O estresse do paciente cirúrgico inicia se, em geral, na hospitalização e acentua se significativamente com a anestesia e o ato operatório, podendo prolongar se na vigência de eventual complicação pós operatória.

A reação orgânica neuroendócrina e metabólica, proporcional à intensidade da agressão e à capacidade de reação do paciente, caracteriza se pela oligúria e retenção de sódio, dependentes da liberação de hormônio anti diurético e aldosterona.

Durante o trauma cirúrgico há retração do volume extracelular funcionante em virtude das perdas externas e da formação do terceiro espaço, perda interna frequientemente olvidada nas prescrições da terapêutica hidroeletrolítica. Shires e cols. demonstra- 
ram que, se quantidades apropriadas de água e eletrólitos são administradas durante a cirurgia, o volume extracelular efetivo pode ser mantido e a oligúria pós operatória evitada.

A queda do volume extracelular funcionante acarreta, como conseqüência da redução na perfusão justa glomerular, estímulo na produção de renina e depois angiotensina e aldosterona por um lado e, como conseqüência da diminuição da pressão no átrio esquerdo, estímulo na liberação de hormônio antidiurético pelo sistema hipotálamo hipofisário por outro lado; da liberação aumentada do hormônio anti diurético e da aldosterona resulta retenção de água e de sódio. Essas reações hormonais constituem parte da reação orgânica geral ao trauma e, em última análise, promovem o restabelecimento da volemia normal.

Segundo Crandell, a reação orgânica ao trauma, no que se refere à liberação de aldosterona e de hormônio anti diurético, pode ser abreviada e menos intensa, com manutenção da volemia normal, se precocemente for evitada a queda do volume extracelular, mediante administração adequada e precoce de água e sódio.

A hidratação sustentada, mediante administração de água e sal nos períodos pré, intra e pós operatórios visa à compensação adequada das perdas externas e internas, e constitui o método de eleição para as grandes cirurgias, principalmente quando as perdas para o terceiro espaço são significantes.

Não é possível na prática estimar com precisão, durante o ato operatório, as perdas pela exposicão de vísceras nem a perda interna no terceiro espaço, o que prejudica a estimativa do volume da solução a ser administrada. Infunde se geralmente, de 2 a $10 \mathrm{ml}$ de solução salina por quilo de peso corporal por hora de cirurgia, o que pode induzir erros, resultando em desidratação ou superhidratação graves, sobretudo em pacientes criticamente doentes; o rim normal pode corrigir o excesso de água e de eletrólitos dentro de determinados limites; esses limites são menores no idoso e nos pacientes com lesão renal.

Pacientes que vão ser submetidos a operações de grande porte e pacientes críticos devem ser monitorizados desde o pré operatório, pelo menos com medida do volume urinário horário e da pressão venosa central, com oferta de líqüidos suficiente para manter volume urinário horário entre 30 e $60 \mathrm{ml}$ e sem aumento significante da pressão venosa central. O aumento da pressão venosa central acima da normalidade corresponde, em princípio, a excesso de oferta de água para as condições cardíacas vigentes.
A monitorização na cirurgia é importante para a definição do volume e qualidade da solução a se administrar, e da velocidade de reposição; são importantes na monitorização o débito urinário, pressão venosa central, dados fornecidos pelo capnógrafo, oxígrafo e cardiógrafo.

A pesagem das compressas e a medida do sangue aspirado auxiliam na estimativa do volume de sangue perdido. A hemoglobina e o hematócrito somente são bons parâmetros para estimar o sangue perdido quando a volemia for normal. A transfusão de componentes do sangue depende do conjunto de alterações clínicas e laboratoriais.

\section{3- Hidratação pós-operatória}

Após a cirurgia, por período de tempo variável, os pacientes permanecem, geralmente, em jejum e com hidratação parenteral, em virtude da anestesia e do íleo adinâmico, mesmo que as operações não correspondam a intervenções sobre o sistema digestivo.

Logo que possível, deve se restabelecer a via oral quando então a compensação de eventuais distúrbios hidroeletrolíticos se faz adequada e rapidamente. Não raramente a via oral pode não ser factível, mas pode ser viável a utilização da via enteral, que é preferível à parenteral.

Se as operações são de pequeno porte, principalmente se não envolvem laparotomia, a hidratação pós operatória é curta, pode restringir se a 500 a 1000 ml de solução isotônica, glicosada a 5\% ou salina, administrada em poucas horas. O restabelecimento precoce da via oral provê, facilmente, os arranjos necessários. Para herniorrafia inguinal, sob anestesia local ou peridural, a hidratação parenteral pós-operatória pode ser interrompida tão logo o paciente esteja bem consciente e ativo, sem náuseas ou vômitos, e corresponde geralmente apenas ao volume residual do frasco da solução instalado durante o ato anestésico.

A mesma conduta é, em princípio, adotada para pacientes submetidos à cirurgia ambulatorial, incluindo grande parte dos submetidos à colecistectornia videolaparoscópica que, por ser mini invasiva, resulta em resposta orgânica neuroendócrina e metabólica discreta.

Nas operações de grande porte, a seqüestração de água e eletrólitos freqüentemente é significante e o íleo adinâmico é prolongado, exigindo hidratação parenteral por vários dias. Se a reposiçao não for suficiente, compensando inclusive as perdas internas, a hipovolemia resultante representa um estímulo adicional para liberação de hormônio anti diurético e aldos- 
terona, com conseqüente redução da diurese que pode atingir volumes menores que $500 \mathrm{ml}$ de urina por dia.

As perdas eventuais por via digestiva e a urinária podem ser medidas e a perda pela perspiração pode ser estimada satisfatoriamente; entretanto, o líquiido perdido no terceiro espaço não pode ser calculado com precisão.

O balanço hidroeletrolítico diário, em que são cotejadas as entradas e perdas de água e de eletrólitos $\left(\mathrm{Na}^{+}, \mathrm{CI}^{-}\right.$e $\left.\mathrm{K}^{+}\right)$, pode evitar erros grosseiros na fluidoterapia em pacientes nos quais o terceiro espaço é pequeno, sobretudo se com o reforço de determinações séricas periódicas desses eletrólitos e do hernatócrito, além da determinação diária da densidade urinária. A freqüência da determinação dos eletrólitos e do hematócrito varia de acordo com a situação clínica e o estado hidroeletrolítico.

É possível ocorrer desidratação por seqüestro de líquiido na área de lesão cirúrgica e na luz intestinal. Esta perda para o terceiro espaço faz se às expensas do LEC normal e reduz o seu volume efetivo, produzindo hemocentração, hipovolemia e redução da diurese. A terapêutica baseada no balanço hidroeletrolítico geralmente subestima esta perda interna. A terapêutica adequada com soluções salinas ou balanceadas em sais e, eventualmente, plasma restaura o volume plasmático. As perdas para o terceiro espaço precisam ser repostas, porque o líqüido sequiestrado transitoriamente não participa das trocas e não tem valor volêmico.

À medida que este espaço diminui, com a estabilização do paciente, ocorre uma auto infusão de líqüido sequiestrado que, se não for eliminado mediante função renal adequada, se transforma em edema intersticial, com possibilidade de conseqüente quadro de insuficiência respiratória aguda do adulto (SARA). Nesta fase de resolução do terceiro espaço há aumento da volemia, com consequiente hemodiluição e redução do hematócrito, e aumento da diurese tanto maior quanto maior for o volume de líqüido previamente sequiestrado. Pode haver erro terapêutico se, com base no balanço hidroeletrolítico, se tentar repor toda a perda urinária. A diurese aumentada é reação natural do organismo para eliminar o excesso de água e a reposição total da diurese pode resultar no excesso de oferta de água. Se o paciente não apresentar boa diurese, deve se restringir líquiidos , usar diuréticos e, se necessário, até processos dialíticos.

O cálculo da oferta de água e eletrólitos baseado no balanço hidroeletrolítico diário é um método bom para as cirurgias nas quais o terceiro espaço é peque- no; entretanto, se o volume do líqüido seqüestrado é grande, apresenta as desvantagens de hidratação insuficiente na fase de formação do terceiro espaço e de hidratação excessiva na fase de resolução. Outra desvantagem desse método de hidratação está relacionada ao fato de a estimativa de perdas de eletrólitos na urina e nas secreções digestivas ser feita com base em valores médios de populações estudadas que podem não raramente ser muito diferentes da perda individual real, pelo que é importante a complementação com a avaliação clínica diária e laboratorial periódica.

Nas grandes cirurgias é recomendada a hidratação sustentada antes, durante e após a cirurgia, mantendo se volume urinário entre 30 e $60 \mathrm{ml}$ por hora, aliada à monitorização complementar necessária, clínica e laboratorial. Neste esquema terapêutico, o número de gotas da solução administrada varia de acordo com o volume urinário horário e a monitorização complementar que, em grande parte dos pacientes, pode ser feita com a simples medida periódica da pressão venosa central. Diurese normal, em princípio, corresponde à perfusão renal e hidratação adequadas e terceiro espaço compensado. Aumenta se o número de gotas por minuto se o volume urinário é baixo (menor que $30 \mathrm{ml}$ ) e diminui se o número de gotas se o volume urinário horário é alto (maior que $60 \mathrm{ml}$ ).

Cuidados especiais, envolvendo acompanhamento e monitorização mais rigorosos, devem ser tomados para pacientes idosos e/ou criticamente doentes.

É importante, para a correta prescrição da hidratação, se conhecer as necessidades diárias do paciente.

No paciente bem hidratado, a necessidade de água no pós-operatório corresponde aproximadamente a $3035 \mathrm{ml} / \mathrm{kg}$ de peso corpóreo, o que em um paciente de $70 \mathrm{~kg}$ equivale a 2100 a $2450 \mathrm{ml} / \mathrm{dia}$.

A necessidade média de sódio é de $100 \mathrm{mEq} /$ dia, de cloro de $80 \mathrm{mEq} /$ dia e de potássio de $60 \mathrm{mEq} /$ dia.

A necessidade mínima diária de calorias varia com a idade e peso corporal (Tabela VI).

Cada grama de glicose ou de proteína fornece $4 \mathrm{kcal}$ e cada grama de gordura fornece $9 \mathrm{kcal}$.

Um grama de glicose hidratada fornece $3,4 \mathrm{kcal}$, portanto $2000 \mathrm{ml}$ de solução glicosada $5 \%$ ou $1000 \mathrm{ml}$ de solução glicosada $10 \%$ equivalem a $340 \mathrm{kcal}$ e suprem as necessidades mínimas de calorias de um paciente de $60 \mathrm{~kg}$. A administração de $100 \mathrm{~g}$ de glicose são suficientes para evitar a cetose do jejum e reduzir pela metade o catabolismo protéico. 
Tabela VI: Necessidade mínima diária de calorias de acordo com a idade

\begin{tabular}{lr}
\hline Idade & $\mathrm{kcal} / \mathrm{kg}$ \\
\hline Crianças de 3 a 4 anos & 20 \\
Crianças com mais de 4 anos & 10 \\
Adulto & 6 \\
\hline
\end{tabular}

Soluções com eletrólitos e glicose estão disponíveis no comércio, sendo a quantidade de eletrólitos expressa em gramas.

Para o cálculo do número de $\mathrm{mEq}$ dos eletrólitos contidos nessas soluções usa se a seguinte fórmula:

$$
\mathrm{mEq} / \mathrm{l}=\frac{\mathrm{mg} \% \times 10 \times \text { valência }}{\text { peso atômico }}
$$

Ceneviva R, Vicente YAMVA. Hydroelectrolytic balance and hydration in surgical patients. Medicina (Ribeirão Preto) 2008; 41 (3): 287-300.

ABSTRACT: A fundamental basis of clinical surgery is the patients' hydroelectrolytic balance. In conjunction with this topic, the distribution of electrolytes aming the hydric compartments, the relation between water gain and water loss, and the main hydroelectrolytic disturbances are discussed. Furthermore, both the hydration and the electrolytic replacement in surgery patients are emphasized.

keywords: Fluid therapy. Water-Electrolyte Balance. Surgery.

\section{BIBLIOGRAFIA RECOMENDADA}

1 - Ayus JC, Caramelo C. Sodium and potassium disorders. In: Shoemaker WC, Ayres SM, Grenvik A, Holbrook PR. Textbook of Critical Care. 4th ed. WB Saunders Co., Philadelphia. 2000: 85361.

2 - Rotellar E. ABC dos Transtornos Eletrolíticos. Trad. Ramos AV. Atheneu, Rio de Janeiro, 1968.

3 - Ferreira EAB. Equilíbrio hidroeletrolítico e cirurgia, In: Barbosa H. Controle Clínico do Paciente Cirúrgico. 6ª ed. Atheneu, São Paulo, 1992; 113-24.

4 - Freire ECS. Equilíbrio hidroeletrolítico em cirurgia. In: Vieira OM, Chaves CP, Manso JEF, Eulálio JMR. Clínica Cirúrgica. Fundamentos Teóricos e Práticos. Atheneu, São Paulo 2000; 13-26.

5 - Shires T, Williams J, Brown F. Acute change in extracelular fluid associated with major surgical procedures. Ann. surg. 1961; 154: 803.
6 - Crandell WB. Parenteral fluid therapy. Surg. clin. North America. 1968; 48: 707.

7 - Piccinato CE, Ceneviva R, Martins ACP, Moriya T, Cherri J. Estudo comparativo de três tipos de hidratação em pacientes submetidos à cirurgia eletiva. Rev. Assoc. Med. Bras. 1981; 27: 83 .

8 - Moore FD. Resposta metabólica à lesão. In Colégio Americano de Cirurgiões: Manual de Cuidados Pré e Pós Operatórios. Guanabara Koogan, Rio de Janeiro, 1969.

9 - Brensilver JM, Goldberger E. Introdução às Síndromes de Equilíbrio Hídrico, Eletrolítico e Ácido Básico. 8ª ed. Artes Médicas, Porto Alegre, 1997.

Recebido para publicação em 20/08/2008

Aprovado para publicação em 30/09/2008 